\title{
Optimizing Student Team Skill Development using Evidence-Based Strate- gies-NSF Award 1431694
}

\section{Dr. Matthew W. Ohland, Purdue University}

Matthew W. Ohland is Professor of Engineering Education at Purdue University. He has degrees from Swarthmore College, Rensselaer Polytechnic Institute, and the University of Florida. His research on the longitudinal study of engineering students, team assignment, peer evaluation, and active and collaborative teaching methods has been supported by over $\$ 14.5$ million from the National Science Foundation and the Sloan Foundation and his team received Best Paper awards from the Journal of Engineering Education in 2008 and 2011 and from the IEEE Transactions on Education in 2011. Dr. Ohland is Chair of the IEEE Curriculum and Pedagogy Committee and an ABET Program Evaluator for ASEE. He was the 2002-2006 President of Tau Beta Pi and is a Fellow of the ASEE and IEEE.

\section{Dr. Misty L. Loughry, Georgia Southern University}

Misty L. Loughry is a Professor of Management at Georgia Southern University, where she teaches strategy and organizational behavior. She received her Ph.D. in management from University of Florida and was on the management faculty at Clemson University. Prior to her academic career, she had a ten-year career in banking. Dr. Loughry's research focuses on teamwork and social control in organizations. She is a co-developer of the CATME system of web-based tools to develop students' team skills. She has been a co-principal investigator on three National Science Foundation (NSF) grants totaling \$4.3 million. Her research has been published in 12 academic journals and presented at 49 conferences.

\section{Dr. David Jonathan Woehr}

David J. Woehr is currently Professor and Chair of the Department of Management at The University of North Carolina at Charlotte. He received his Ph.D. in Industrial/Organizational Psychology from the Georgia Institute of Technology in 1989. Dr. Woehr served on the faculty of the Psychology Department in the I/O Psychology program at Texas A\&M University from 1988 to 1999 and as a Professor of Management at the University of Tennessee from 1999 to 2011 . He has also served as a Visiting Scientist to the Air Force Human Resource Laboratory and as a consultant to private industry. Dr. Woehr is a fellow of the Society for Industrial and Organizational Psychology (SIOP), the American Psychological Association (APA), and the Association for Psychological Science (APS). His research on managerial assessment centers, job performance measurement, work related attitudes and behavior, training development, and quantitative methods has appeared in a variety of books, journals, as papers presented at professional meetings, and as technical reports. Dr. Woehr currently serves as editor for Human Performance as well as on the editorial boards for Organizational Research Methods, and the European Journal of Work and Organizational Psychology

\section{Richard . Layton, Rose-Hulman Institute of Technology}

Richard Layton is an Associate Professor of Mechanical Engineering at Rose-Hulman Institute of Technology. He received a B.S. from California State University, Northridge, and an M.S. and Ph.D. from the University of Washington. His areas of scholarship include student teaming, longitudinal studies of engineering undergraduates, and data visualization. His teaching practice includes formal cooperative learning and integrating communications, ethics, and teaming across the curriculum. He is a founding developer of the CATME system, a free, web-based system that helps faculty assign students to teams, conduct selfand peer-evaluations, and provide rater training. He can occasionally be found playing guitar at a local open mic.

\section{Dr. Daniel Michael Ferguson, Purdue University, West Lafayette}

Daniel M. Ferguson is the recipient of four NSF awards for research in engineering education and a research associate at Purdue University. Prior to coming to Purdue he was Assistant Professor of Entrepreneurship at Ohio Northern University. Before assuming that position he was Associate Director of 
the Inter-professional Studies Program and Senior Lecturer at Illinois Institute of Technology and involved in research in service learning, assessment processes and interventions aimed at improving learning objective attainment. Prior to his University assignments he was the Founder and CEO of The EDI Group, Ltd. and The EDI Group Canada, Ltd, independent professional services companies specializing in B2B electronic commerce and electronic data interchange. The EDI Group companies conducted syndicated market research, offered educational seminars and conferences and published The Journal of Electronic Commerce. He was also a Vice President at the First National Bank of Chicago, where he founded and managed the bank's market leading professional Cash Management Consulting Group, initiated the bank's non credit service product management organization and profit center profitability programs and was instrumental in the breakthrough EDI/EFT payment system implemented by General Motors. Dr. Ferguson is a graduate of Notre Dame, Stanford and Purdue Universities and a member of Tau Beta Pi. 


\section{Optimizing Student Team Skill Development using Evidence-Based Strategies}

\section{Introduction}

Determining when and how students learn team skills, and why some students fail to do so, requires complex experimental research and documentation of individual student outcomes. This research requires large numbers of teams and multi-level analysis and is not easy to do, yet recent research shows promise. A recent study showed that students who used a consistent online peer evaluation system (a proprietary system at a Canadian university) had higher peer ratings on a subsequent team than students with similar team experiences who had not used the peer evaluation system. ${ }^{1}$ Another study showed that peer evaluations made students aware of how their peers perceive them, building self-awareness. ${ }^{2}$ A third study showed that using the university's proprietary peer evaluation system made students more confident at rating teammates and improved their ability to communicate performance information to teammates. ${ }^{3}$

The proposed research will extend this line of research to better understand how particular uses of peer evaluations and other interventions affect the learning of team skills. Unlike the research cited above, the proposed research will use a peer evaluation system that is freely available without cost and widely used in higher education. The CATME tools are based on teamwork research, evidence for their validity has been published, and they are used by over 6500 faculty at over 1200 institutions in 62 countries. The peer-evaluation instrument can be previewed at www.CATME.org. Although the tools were developed to help instructors manage teams, ${ }^{4,5}$ they can also facilitate research on students' learning and document student outcomes related to learning and the quality of their team experiences. ${ }^{6}$ We propose seven empirical studies to measure the effect sizes of the following learning experiences: teamwork training, working in teams, rating teamwork, and giving and receiving feedback.

\section{Research Overview}

The research plan illustrated by Figure 1 shows our outcomes (in rectangles), the strategies by which we expect to achieve them (in ovals), and the studies by which we will measure the connections (arrows). The model is informed by prior research. To establish the relationships shown, seven studies are needed - some to be sure that our work agrees with earlier research findings, some because the literature is unclear on a particular issue, and some because there is no literature at all. 


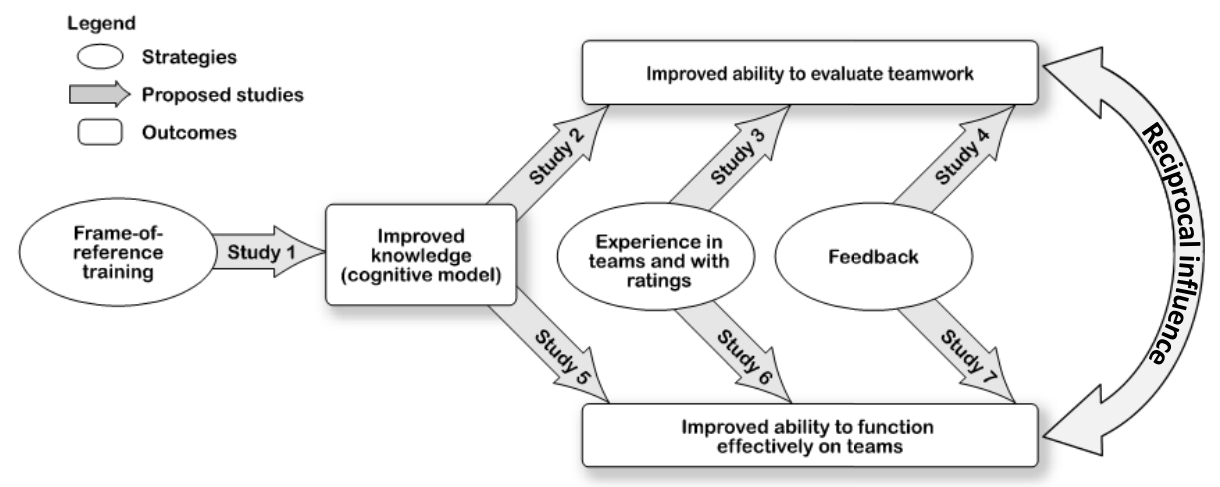

Figure 1. Model for improving self- and peer-evaluation skills and teaming skills.

Study 1 will measure the differences between trained and untrained participants in recalling, recognizing, and categorizing team behaviors.

Study 2 will (1) show that participants with a more accurate cognitive model of teamwork have better self- and peer-evaluation skills than untrained participants as measured by their ability to accurately classify teamwork behaviors. (2) Show that participants required to justify their ratings rate more accurately. Varying the rater training is used to achieve more variance in the independent variable (the accuracy of participants' cognitive model of teamwork) than would naturally occur.

Study 3 will show that students who use a particular peer evaluation system repeatedly have self-ratings of their team contributions that are more modest compared to how their teammates rate them than do participants who have not previously used the peer evaluation system. This will demonstrate that experience using a consistent peer evaluation system is associated with metacognitive learning, specifically the ability to accurately perceive one's own skill level. ${ }^{2}$ Prior research shows that this greater selfunderstanding is evidence of learning; in other words, these metacognitive gains are evidence of concomitant cognitive gains. ${ }^{7,8}$

Study 4 will determine whether giving students feedback on the degree to which their ratings match those of other raters improves their rating practices.

Study 5 will explore the effect of cognitive model development (measured by a knowledge test as in Study 2) on team performance and team-member effectiveness. Training members of teams to develop a more accurate cognitive model of teamwork should increase team performance, team cohesion, team self-efficacy, and satisfaction, and reduce team conflict.

Study 6 will explore the effect of structured team experiences and use of a peer evaluation system on team skills and team-member effectiveness. Prior research has found that completing peer evaluations familiarizes students with team skills ${ }^{9,10}$ and improves new teammates' satisfaction with those team members on a future team. ${ }^{1}$

Study 7 will explore the effect of five feedback alternatives on team performance, satisfaction, team cohesion, team efficacy and team conflict: (1) self and peer evaluation 
data collected but no feedback given, (2) feedback by the peer evaluation system, (3) personal coaching by instructional staff, and (4) personal coaching by instructional staff and feedback from the peer evaluation system, and (5) no self or peer evaluation data collected nor feedback given (comparison group). All protocols involve faculty partners who assign students to teams to perform team assignments as a required part of the courses. All researchers have experience doing team-skills coaching and will jointly develop a coaching protocol. One or more of these investigators will train faculty partners to follow that protocol when using the coaching intervention. Faculty partners will document their coaching activities.

\section{Acknowledgment}

This work was supported in part by NSF award 1431694, Optimizing Student Team Skill Development using Evidence-Based Strategies.

\section{References}

${ }^{1}$ Brutus, S., \& Donia, M. B. (2010). Improving the effectiveness of students in groups with a centralized peer evaluation system. Academy of Management Learning \& Education, 9, 652-662.

${ }^{2}$ Mayo, M., Kakarika, M. Pastor, J.C., \& Brutus, S. (2012). Aligning or inflating your Leadership self-image? A longitudinal study of responses to peer feedback in MBA teams. Academy of Management Learning \& Education, 11, 631-652.

${ }^{3}$ Brutus, S., \& Donia, M. B., \& Ronen, S. (2013). Can business students learn to evaluate better? Evidence from repeated exposure to a peer evaluation system. Academy of Management Learning \& Education, 12, 18-31.

${ }^{4}$ Ohland, M. W., Bullard, L. F., Felder, R. M., Finelli, C. J., Layton, R. A., Loughry, M. L., and Schmucker, D. G. (2005). The Comprehensive Assessment of Team-Member Effectiveness. https://engineering.purdue.edu/CATME/CATME-brochure.pdf

${ }^{5}$ Layton, R. A., Ohland, M. W., and Loughry, M. L. (2007). The Team-Maker. https://engineering.purdue.edu/CATME/Team-Maker-brochure.pdf

${ }^{6}$ Loughry, M.L., Ohland, M.W., \& Woehr, D.J. (2014). Assessing Teamwork Skills for Assurance of Learning Using CATME Team Tools," Journal of Marketing Education, 36(1), 5-19, April 2014.

${ }^{7}$ Ehrlinger, J., Johnson, K., Banner, M. Dunning, D. \& Kruger, J. (2008). Why the unskilled are unaware: Further explorations of (absent) self-insight among the incompetent. Organizational Behavior and Human Decision Processes, 105, 98-121.

${ }^{8}$ Kruger, J. \& Dunning, D (1999). Unskilled and unaware of it: How difficulties in recognizing one's own incompetence lead to inflated self-assessments. Journal of Personality and Social Psychology, 77, 1121-1134. 
${ }^{9}$ Thomas, G., Martin, D., \& Pleasants, K. (2011). Using self- and peer-assessment to enhance students' future-learning in higher education. Journal of University Teaching \& Learning Practice, 8(1), article 5.

${ }^{10}$ Dominick, P. G., Reilly, R. R., \& McGourty, J. W. (1997). The effects of peer feedback on team member behavior. Group \& Organization Management, 22, 508-520. 